\title{
The Dynamics of Real-Time Classroom Emotions: Appraisals Mediate the Relation Between Students' Perceptions of Teaching and Their Emotions
}

\author{
Thomas Goetz* \\ University of Vienna
}

Oliver Lüdtke

IPN-Leibniz Institute for Science and Mathematics Education, Kiel, and Center for International Student Assessment, Munich

\author{
Melanie M. Keller* \\ IPN-Leibniz Institute for Science and Mathematics \\ Education, Kiel \\ Ulrike E. Nett \\ University of Augsburg
}

\author{
Anastasiya A. Lipnevich \\ The City University of New York
}

\begin{abstract}
Guided by Pekrun's (2006) control-value theory of achievement emotions, we investigated the mediating role of control and value appraisals in the relations between students' perceptions of teaching and their academic emotions. To account for the highly fluctuating and dynamic nature of emotions, we used the experience sampling method complemented by within-person mediation analyses. In 2 studies, $n=122$ (Study 1) and $n=149$ (Study 2) high school students reported on their real-time perceptions of teaching characteristics (grouped into two second-order factors: supportive presentation style and excessive lesson demands), their control and value (intrinsic and extrinsic) appraisals, and their academic emotions of enjoyment, anxiety, and boredom ( $n=1,520 / 2,669$ assessments within students). Across the 2 studies, we found consistent results on the intraindividual level that are in line with an assumption of the control-value theory: Appraisals of control and value mediated the effects of perceived characteristics of teaching on academic emotions (e.g., supportive presentation style showed positive effects on control, which, in turn, showed positive effects on enjoyment). At the same time-and contributing to further developments of the control-value theory-the relative importance of direct and indirect effects (i.e., amount of mediation) differed across emotions. For example, there was a strong direct effect of supportive presentation style on enjoyment, but no effect on anxiety. Similarly, appraisals differed in their relative importance as mediators both within and across emotions (e.g., extrinsic value was mainly relevant for anxiety, whereas intrinsic value contributed to enjoyment and boredom).
\end{abstract}

\section{Educational Impact and Implications Statement}

Theories do not only systematize a large number of phenomena in a coherent way, but also serve to make specific predictions that can be tested in empirical studies. This study examined one central assumption of a key educational psychological theory, the control-value theory of achievement emotions. We found that, as predicted, aspects of classroom instruction influenced students' judgments (i.e., cognitive appraisals) of how much control they had over events and how much they valued the activity. These appraisals, in turn, influenced students' experiences of enjoyment, anxiety, and boredom. In addition to supporting key assumptions of the theory, our findings could prove fruitful in the future, for instance when developing targeted interventions to improve students' emotional lives in the classroom.

Keywords: teaching, instruction, appraisals, emotions, experience sampling method

Supplemental materials: http://dx.doi.org/10.1037/edu0000415.supp

Thomas Goetz, Department of Psychology, University of Vienna; Melanie M. Keller, Department of Physics Education, IPN-Leibniz Institute for Science and Mathematics Education, Kiel; Oliver Lüdtke, Department of Educational Measurement, IPN-Leibniz Institute for Science and Mathematics Education, Kiel, and Center for International Student Assessment, Munich; Ulrike E. Nett, Empirical Educational Research, University of Augsburg; Anastasiya A. Lipnevich, Queens College and the Graduate Center, The City University of New York.
This research (Study 2) was supported by a grant from the Swiss National Science Foundation (SNSF) to Thomas Goetz (100014_ 131713/1)

${ }^{*}$ Thomas Goetz and Melanie M. Keller contributed equally to this article.

Correspondence concerning this article should be addressed to Melanie M. Keller, Department of Physics Education, Leibniz-Institute for Science and Mathematics Education, Olshausenstr. 62, D-24118 Kiel, Germany. E-mail: keller@ipn.uni-kiel.de 
"It is not so much what happens to you as how you think about what happens."

(Epictetus, Greek Stoic philosopher, 55 A.D.-135 A.D.)

In the last 15 years, there has been a steady increase in studies on emotions experienced at school (Pekrun, Muis, Frenzel, \& Goetz, 2018). One of the main reasons behind this growing line of research is the increased understanding of emotions and their relevance to classroom behavior, achievement outcomes, subjective well-being, career choice, and lifelong learning (Frenzel \& Stephens, 2013). Because of numerous well-established effects of emotions on core educational outcomes, understanding antecedents of emotions in a school context is critically important.

Theoretical approaches and scattered empirical findings suggest that teaching is a key antecedent of students' emotions in the classroom (e.g., Frenzel, Goetz, Lüdtke, Pekrun, \& Sutton, 2009). According to Pekrun's (2006) control-value theory of achievement emotions (CVT), teaching may be assumed to have an effect on students' emotions via their cognitions. The latter include perception and evaluation of their learning environment, especially cognitive appraisals of control (e.g., judgment of own competence) and value (e.g., judgment of intrinsic and extrinsic value of the task). Interestingly, the idea that thoughts play a key role in mediating the effects of the environment on our emotions traces its roots to the center of stoic philosophical tradition dating more than 2,000 years (e.g., Epictetus, as cited by Long, 1991; see proverb at the beginning).

The aim of this study was to investigate this assumed mediating role of control and value appraisals in the relations between students' perceptions of teaching and their emotions. In so doing and because of highly dynamic and context-dependent nature of emotions (Nett, Bieg, \& Keller, 2017), we used the experience sampling method (Hektner, Schmidt, \& Csikszentmihalyi, 2007), which is characterized by high ecological validity (Bolger, Davis, \& Rafaeli, 2003; Csikszentmihalyi \& Larson, 1987). This methodological approach was complemented by within-person analyses (Bolger \& Laurenceau, 2013; Murayama et al., 2017) that allow for tracing situational fluctuations of real-time emotions by analytically separating them from between-person differences. As such, the current study adds to extant research by testing a central mediation hypothesis, and by applying a novel methodological approach suited for capturing real-time dynamics in the classroom.

\section{The Control-Value Theory: Cognitive Appraisals as Mediators of Teaching/Emotions Relations}

\section{Theoretical Assumptions}

Appraisal theories of emotions assume that it is not the situation itself that elicits an emotional reaction, but rather the cognitive interpretation, that is, evaluative judgments regarding the situation and its significance for personal well-being and personally relevant goals (Lazarus, 1991). These appraisals do not have to be conscious: They can be automatic or unconscious (see Moors, 2009). Although different appraisals or constellations of appraisals for the emergence of emotions have been proposed, almost all theories include some version of agency and goal significance (see, e.g., Ellsworth \& Scherer, 2003). The major theory in the educational context, the CVT was developed by Pekrun (2006) and also includes these two major appraisals - agency in the form of control, and goal significance in the form of value-as proximal antecedents of students' emotions in the classroom.

In the CVT, aspects of the learning environment are viewed as antecedents of achievement emotions with characteristics of teaching reflecting a core facet of the learning environment at school. Like all appraisal theories, the CVT posits that the learning environment represents a distal antecedent of students' emotions that has an indirect effect on students' emotions via more proximal emotion antecedents, namely, students' cognitive appraisals of control and value. In other words, control and value appraisals are assumed to mediate the effects of teaching characteristics on students' achievement emotions. Although there is evidence that students' emotions may be directly influenced by teachers' emotions and teaching behavior (Bakker, 2005; Frenzel et al., 2009), and although such a direct link between teaching and emotions is also conceivable for selected teaching dimensions in the CVT (e.g., classroom climate or enthusiasm, leading to partial mediation of the effect on students' emotions), evidence is lacking regarding the extent to which teaching directly and indirectly impacts students' discrete emotions.

In Pekrun's (2006) CVT, achievement emotions are defined as emotions related to achievement activities and their success and failure outcomes; outcome emotions can either be prospective and anticipatory (e.g., hope for success) or retrospective (e.g., pride). In the CVT, emotions are further differentiated according to the dimensions of pleasant versus unpleasant (often labeled as positive vs. negative) and activating versus deactivating. According to this taxonomy, prototypical achievement emotions include enjoyment (pleasant, activating), relief (pleasant, deactivating), anxiety (unpleasant, activating), and boredom (unpleasant, deactivating).

These are preceded by control appraisals that are defined as perceptions of one's competence with respect to successful performance of actions and attainment of favorable achievement outcomes (for a discussion about control, see Skinner, 1996). Academic self-concept and self-efficacy are often used to index control appraisals within the scope of the CVT (e.g., Boehme, Goetz, \& Preckel, 2017). Higher control appraisals are assumed to increase pleasant and decrease unpleasant emotions. Value appraisals, on the other hand, pertain to the perceived importance of learning and achievement-related activities and outcomes. Typical variables used to assess value appraisals in the context of the CVT are individuals' intrinsic and extrinsic value (Pekrun, 2006; for a differentiation of value components, see Frenzel, Pekrun, \& Goetz, 2007b; Gaspard et al., 2015). In accordance with the CVT tenets value appraisals should increase all emotions, independent of their valence (i.e., both pleasant and unpleasant emotions). The only notable exception is boredom and it should negatively relate to value appraisals.

\section{Empirical Findings}

The relation between teaching and emotions. One of the key claims of the CVT is that teaching behavior-as one facet of the learning environment in classrooms-should be related to students' achievement emotions. This link is supported by a number of studies that consistently demonstrate that factors contributing to students' pleasant emotions at the same time tend to decrease their unpleasant emotions. For instance, learning 
environments characterized by teacher clarity, effective scaffolding, constructive feedback geared at helping students improve, a motivating and enthusiastic teaching style, and a climate of cooperation and social relatedness are greatly conducive to pleasant emotions (e.g., enjoyment) and at the same time reduce negative emotions (e.g., anger; Becker, Goetz, Morger, \& Ranellucci, 2014; Frenzel et al., 2009; Frenzel, Pekrun, \& Goetz, 2007a; Goetz, Pekrun, Hall, \& Haag, 2006; Kunter et al., 2013). Conversely, achievement pressure and a climate of competition, sanctioning and directly controlling behavior by the teacher, normative comparisons, high pace of instruction, and excessive demands and expectations increase students' experience of unpleasant emotions, such as anxiety, anger, or boredom, and at the same time decrease positive emotions, such as enjoyment and pride (Assor, Kaplan, Kanat-Maymon, \& Roth, 2005; Frenzel et al., 2007a; Goetz et al., 2006; Goetz, Lüdtke, Nett, Keller, \& Lipnevich, 2013; Taylor \& Fraser, 2013).

Findings on the relation between teaching and students' discrete emotions are complemented by studies not addressing discrete emotions per se but focusing on other affective constructs. For example, there is extensive evidence suggesting strong links between specific teaching characteristics and students' interest and interest development (e.g., Bergin, 1999; Mouratidis, Vansteenkiste, Sideridis, \& Lens, 2011) as well as students' intrinsic motivation (e.g., Black \& Deci, 2000). These well-documented relations support the general assumption that teaching and students' emotions are related, even though specific antecedents of discrete emotions and those of other affectively toned variables may differ (see Gogol, Brunner, Martin, Preckel, \& Goetz, 2017).

Methodologically, teaching may be assessed from a position external to the students, for instance via observer or teacher ratings, or internally through capturing student perceptions (Kunter \& Baumert, 2007; Praetorius, Lenske, \& Helmke, 2012). Although research evidence indicates that the extent to which these two perspectives converge depends on the particular teaching dimension under investigation, the validity of student perceptions is generally considered adequate (Wagner et al., 2016; Wagner, Göllner, Helmke, Trautwein, \& Lüdtke, 2013). This somewhat corroborates the aforementioned findings on the relation between teaching and emotions that mostly relied on students' perceptions of teaching - and approach that was also employed in our study. In sum, and consistently with CVT, there is broad evidence suggesting that characteristics of learning environment and teaching serve as antecedents of students' emotional reactions. However, the exact mechanisms of these links are not yet clear.

Appraisals mediating the teaching/emotions relation. Only a few studies conducted in the educational context focused on the mediation assumption of CVT (e.g., Burić, 2015; Goetz et al., 2006). These studies revealed that cognitive appraisals mediated the teaching-emotions relations in students. Teaching characteristics such as clarity and structure, or instructional approaches encouraging cooperation instead of competition were found to induce control appraisals in students, thereby increasing students' pleasant emotions, such as enjoyment, and decreasing unpleasant emotions, such as anxiety or anger (Burić, 2015; Goetz et al., 2006). Similarly, motivating and enthusiastic teaching style increased students' extrinsic value appraisal and thereby decreased boredom (Cui, Yao, \& Zhang, 2017). Conversely, an environment that actively reinforces and promotes achievement was found to increase students' achievement (i.e., extrinsic) value appraisals, which, in turn, exerted a positive effect on enjoyment as well as on anxiety (Goetz et al., 2006). Although one of the central tenets of CVT describes the mediational role of appraisals in teachingemotions relations, the available empirical evidence on this mediation is relatively scarce. Research has focused on selected teaching facets (e.g., enthusiastic teaching in Cui et al., 2017) or selected domains (mathematics in Burić, 2015; Latin in Goetz et al., 2006), however, these studies do not generalize to a broad range of teaching, appraisals, emotions, and academic domains. As a consequence, evidence is lacking on (a) whether appraisals do in fact mediate the effect of teaching on emotions; (b) which appraisals act as mediators for specific teaching facets and emotions; and (c) the relative strength of direct and mediated effects.

Situational fluctuations in emotions. In general, emotions are highly dynamic phenomena with individuals' emotional experiences varying across different situations and contexts (Eid \& Diener, 1999). Specifically suited to test these situational dynamics are momentary assessment methods (for an application outside of education and in the context of appraisal theories of emotion, see also Tong et al., 2005, 2007). In fact, several studies in the educational context have successfully applied these methods to the study of students' emotions. They are unanimous in their findings that students' emotions are highly dynamic and vary strongly from situation to situation (Ahmed, van der Werf, Minnaert, \& Kuyper, 2010; Goetz et al., 2013, 2014; Goetz, Frenzel, Stoeger, \& Hall, 2010; Nett et al., 2017).

The CVT and its mediation assumption acknowledges the dynamic nature of emotions and refers to situational variations within an individual. That is, a student perceiving the learning environment and appraising subjective control and value in a situation in a specific way should respond with the experience of specific emotions in this situation. The same student is assumed to experience other emotions in other situations if those are perceived and appraised by him or her in a different way. In other words, levels of emotions are expected to change within one student according to changes in his or her interpretation of situations.

To systematically describe situational fluctuations in emotions, teaching, and appraisals it is not only necessary to use momentary assessment methods, but to also analytically separate withinperson relations from between-person differences in these phenomena. Several studies have done this, but none of these studies tested the mediation of the teaching-emotion relations via appraisals. For instance, Ahmed et al. (2010) investigated the appraisalemotion relation on the within-person level using the diary method (Bolger et al., 2003) without accounting for distal antecedents (see also study by Goetz, Frenzel, et al., 2010). Similarly, Goetz et al. (2013) used the experience sampling method (Barrett \& Barrett, 2001; Csikszentmihalyi \& Larson, 1987) and investigated the within-person relations between student perceived teaching characteristics and emotions without gauging students' cognitive appraisals.

In sum, there is scattered evidence that comes from betweenperson designs for the assumed mediated effect of teaching on students' emotions via cognitive appraisals. These findings, however, cannot be generalized to the situational and within-person level (see, e.g., Voelkle, Brose, Schmiedek, \& Lindenberger, 2014). In the current study, we tested the mediation assumption as a central tenet of CVT, thereby tracing situational dynamics of 
students' emotional experiences in class by combining momentary assessment with a within-person analytical approach. Thus, our study extends existing findings and advances the field by responding to frequent calls to focus on within-person processes in educational and psychological research (e.g., Molenaar \& Campbell, 2009; Schmitz, 2006).

\section{The Current Study}

Our study aimed to investigate the mediating role of control and value appraisals between characteristics of teaching and students' discrete emotions as proposed by Pekrun's (2006) CVT of achievement emotions. We hypothesized that cognitive appraisals of control and value mediated the effects of student perceived teaching (as a core facet of the learning environment) on students' achievement emotions (see Figure 1). Although this hypothesis is central to CVT, its empirical support is scarce, with evidence coming from generalized (i.e., trait) measures of emotional selfreports. The latter approach can be biased (Robinson \& Clore, 2002) and does not adequately capture high situational withinperson fluctuations of emotions. To account for these methodological specifics and to go beyond previous investigations, we tested the CVT's mediation hypothesis by using the experience sampling method (ESM; e.g., Hektner et al., 2007) that has high ecological validity (Csikszentmihalyi \& Larson, 1987). We complemented this methodological approach by using within-person mediation analyses (Bolger \& Laurenceau, 2013) that allowed for tracing the dynamic nature of students' classroom experiences.

Drawing upon the CVT, we focused on three prototypic emotions that differ along the dimensions of pleasant versus unpleasant and activating versus deactivating: enjoyment (pleasant, activating), anxiety (unpleasant, activating), and boredom (unpleasant, deactivating). We chose not to examine any pleasant deactivating emotions (e.g., relief, relaxation) because these emotions are mainly experienced following an academic achievement situation rather than during such situations, with the latter being the focus of our chosen real-time approach. The three selected emotions also cover object focus as another categorization for achievement emotions suggested by CVT: Enjoyment and boredom are focused on the activity, whereas anxiety is an outcome-related emotion. A further rationale for selecting these three emotions was that they are among the most prevalent and consequential achievementrelated emotions experienced by students in a typical classroom context. For instance, there are numerous studies showing that enjoyment is in fact the most common pleasant emotion, and is highly predictive of achievement-related outcomes (Pekrun, Goetz, Frenzel, Barchfeld, \& Perry, 2011; Pekrun, Lichtenfeld, Marsh, Murayama, \& Goetz, 2017). As enjoyment's unpleasant counterpart, anxiety has been shown to be widely experienced by students in a school context, and its negative links to meaningful academic outcomes have been well-documented (see e.g., Zeidner, 2007). Finally, boredom dominates achievement emotions as the most prevalent emotion experienced in a classroom. Similarly to anxiety, its negative effects on learning-related outcomes have been well established (Goetz et al., 2014; Pekrun, Goetz, Daniels, Stupnisky, \& Perry, 2010; Pekrun, Hall, Goetz, \& Perry, 2014).

In Study 1, we reanalyzed data of an experience sampling study by Goetz et al. (2013, with German high school students) and included control and value appraisals as potential mediators in the teaching/ emotions relations, which were not part of prior analyses. Goetz et al. (2013) examined whether students' perceived characteristics of teaching directly was related to a wide range of students' emotions and whether there were domain-specific differences in these relations. Student perceived teaching was operationalized via two factors: supportive presentation style (delineating an illustrative and motivating teaching style) and excessive lesson demands (delineating high difficulty and fast pace). The study revealed that a supportive presentation style had positive effects on enjoyment and negative effects on boredom, whereas excessive lesson demands showed negative effects on enjoyment and positive effects on anxiety and boredom. Another important finding of Goetz et al. (2013) study was that the relations between teaching characteristics and academic emotions were rather similar across academic domains (i.e., mathematics, physics, German, English). Hence, in the study herein reported we did not model academic subjects and investigated relations across multiple domains.

The goal of the second experience sampling investigation (Study 2) was to extend the results of Study 1 and evaluate whether the latter findings generalized to a different age of students (Grades 8 and 11 in Study 1, Grade 9 in Study 2) and to a different country (Germany in Study 1, Switzerland in Study 2).

\section{Method}

\section{Procedure}

In both ESM studies at the beginning of the data collection cycle students reported on demographics and other variables in a paper-

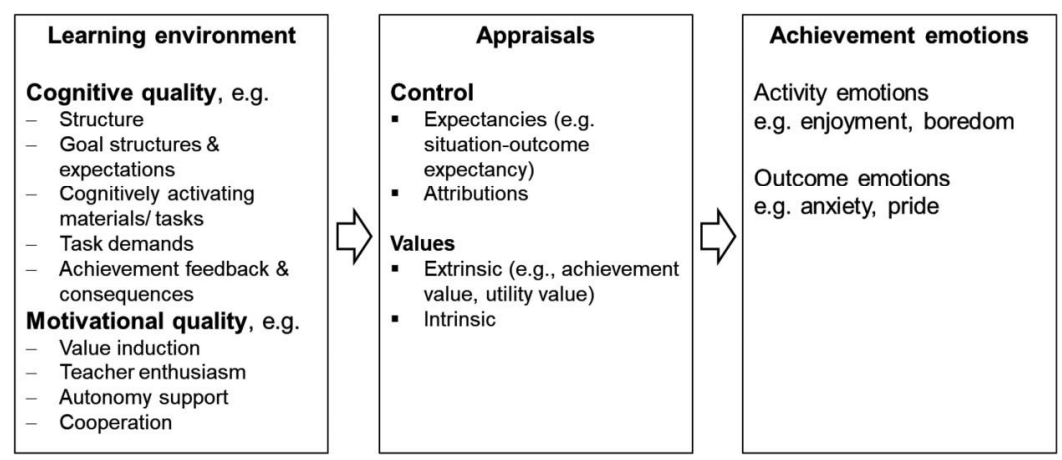

Figure 1. Mediation assumption based on Pekrun's (2006) control-value theory on achievement emotions. 
and-pencil questionnaire. Out of all students who completed the demographic questionnaire, two to four students per class were randomly selected to participate in the ESM assessment; randomization occurred within classes to achieve the final number of two to four students per class. All ESM participants received an electronic device (personal digital assistant, PDA, in Study 1; iPod Touch in Study 2), which had been programmed in advance with study questions. Items on perceived teaching characteristics, cognitive appraisals, and emotional experiences were displayed one at a time, and students were instructed to immediately complete them. It took students about one minute to complete each set of items.

The ESM assessment took place only during regular classes to make sure that exams were not interrupted. The studies used a combination of event and random sampling (Hektner et al., 2007). Prior to target lessons, students activated the device (event sampling). Upon activation and once in the following $40 \mathrm{~min}$, the device would randomly signal and prompt students to report (random sampling). This sampling procedure allowed us to include a broad variety of classroom situations. By including students from different classes, by investigating four different subject domains that are usually taught by different teachers, and by spreading the assessment over a period of several school days, the procedure produced a comprehensive picture of students' daily experiences in the classroom.

\section{Sample}

Study 1. A total of 122 German students ${ }^{1}$ from Grades 8 and 11 of Gymnasium, the high-achieving track in the three-track German school system (approximately $40 \%$ of students in a cohort attend Gymnasium), participated in Study 1 . Students' average age was 16 years overall $(M=14.32, S D=0.52$ in Grade $8, M=$ $17.54, S D=0.54$ in Grade 11). Students were randomly selected from 41 classrooms (21 classrooms from Grade 8 and 20 from Grade 11) of seven schools and were invited to participate in the ESM assessment. Data were collected over a period of 10 school days during the final three months of the academic year. The lessons targeted in Study 1 spanned the subjects of mathematics, physics, German, and English, resulting in a total number of 1,520 state assessments and an average of 12.46 assessments per student. $^{2}$

Study 2. A total of 149 students were randomly selected from 44 ninth-grade classes from upper-track secondary schools (Gymnasium) in the German speaking part of Switzerland for participation in the ESM assessment. Students were, on average, 15.64 years old $(S D=0.62$ years) and $54 \%$ of them were female. The data were collected over a period of 10 school days during the second term of the academic year. Lessons covered in the state assessments in Study 2 were mathematics, German, English, and French, resulting in 2,669 assessments, an average of 17.91 assessments per student.

The wider school context in secondary schools of Gymnasium is rather similar in Germany and Switzerland. A fixed group of students remain together as a class throughout the school year and across the different school subjects, which are usually taught by different teachers. Between the two countries and across the grade levels (Grades 8, 9, and 11), the number of lessons per week and subject may vary depending on whether it's a main subject (usu- ally the case for German, first foreign language, and mathematics) or a secondary subject (e.g., physics). On average, the classes are somewhat smaller in Switzerland than in Germany (24 in Germany and 19 in Switzerland for lower secondary school; OECD, 2017).

\section{Instruments}

Assessment and selection principles. To avoid overly intrusive assessments both studies employed single items to assess the key concepts of the study. Single-item measures are common in ESM studies (e.g., Ahmed et al., 2010; Goetz, Frenzel, et al., 2010) and have been shown to have adequate psychometric characteristics (Gogol et al., 2014; Wanous, Reichers, \& Hudy, 1997) and provide a viable alternative when long scales are not applicable. For instance, Gogol and colleagues (2014) investigated two core motivational constructs, academic self-concept and anxiety, and found that correlation patterns with external criteria (i.e., academic achievement) were similar for long scales and single items. For the present ESM assessments, we chose single items on the basis of high content validity in combination with the evidence of itemscale characteristics from long scales included in previous studies. We adapted the selected item wordings to suit the momentary assessment. The two studies used comparable but not identical item wording for the key constructs. In Study 1 we asked students' to report their experiences during this lesson (e.g., "How much anxiety are you experiencing during this class?"), whereas in Study 2 the item wording reflected their at-the-moment experiences (e.g., "At the moment, I am anxious"). All items are provided in Table A1 in the Appendix.

With regards to cognitive appraisals, the current study targeted the central antecedents - subjective control and value-as outlined in Pekrun's (2006) CVT of achievement emotions. The control appraisal, which targeted students' perceived capabilities, has been successfully implemented in numerous previous studies in the context of CVT (e.g., Boehme et al., 2017; Pekrun, Goetz, Titz, \& Perry, 2002). The appraisal of value referred to subjectively perceived relevance and importance of an activity and outcome in the classroom. The two studies differentiated intrinsic from extrinsic value. Intrinsic value gauged whether students valued the subject (Study 1) or the lesson (e.g., mathematics; Study 2) for their own sake. Conversely, extrinsic value focused on the extent to which students valued obtaining good grades. Grades are the major external achievement-related reward in the German/Swiss upper

\footnotetext{
${ }^{1}$ In Study 1, the total of 122 students participated in the ESM assessment. Two of these students did not provide information on demographics and trait assessments. Because the focus of the present study was on intraindividual relations, these two students were nonetheless included in the current analyses yet excluded from the Goetz et al. (2013) study that reported findings based on 120 students. As a result of this difference and because different analytical procedures and statistical programs were used estimates in the present study and this previous publication may slightly differ.

${ }^{2}$ When students answered to a signal, they sometimes did not report on all variables. The extent to which they missed one or more variables per assessment varied. Study 1 covered 1,520 assessments of which 1,499 $(98.6 \%)$ were complete (i.e., had no missing on any variable). On eight assessments, students reported only their emotions; all other missing data patterns were negligible. Study 2 covered overall 2,669 assessments of which 2,195 (82\%) were complete. Three hundred eighty-five assessments (14\%) had a missing only on the perceived teacher enthusiasm item. All further missing data patterns were negligible in numbers.
} 
secondary school system and are expected to be salient in almost every school lesson, albeit to a varying degree. These two forms of value appraisals have been consistently shown to differentially relate to students' emotions: intrinsic value is assumed to increase pleasant and lower unpleasant emotions, whereas extrinsic value is assumed to increase both pleasant and unpleasant emotions (Goetz et al., 2006; Goetz, Frenzel, et al., 2010). Boredom is a notable exception to this pattern: Both types of value appraisals should negatively relate to boredom. Finally, and in regards to students' emotions, their experiences of enjoyment, anxiety, and boredom were assessed to allow for comparisons across the two studies and samples (for the selection of those emotions, see above).

\section{Study 1.}

Teaching characteristics. Study 1 data had been previously analyzed to answer a different research question in an earlier publication (Goetz et al., 2013). These results provided a starting point for the present study analyses. Eight items that assessed students' perceptions of teaching during the lesson were used. In Goetz et al. (2013), a within-person exploratory factor analysis grouped the eight items into two factors. The first factor (F1) delineated a supporting presentation style (items on understandability, enthusiasm, illustration, fostering attention), and the second factor (F2) captured excessive lesson demands (items on difficulty, pace, lack of clarity, and teachers' level of expectations). All items were rated on a 5-point scale ranging from 1 (strongly disagree) to 5 (strongly agree). Items pertaining to the two factors were averaged and used as manifest indicators in all of the analyses described below. Reliability of the teaching factors was estimated via the omega coefficient, which draws on multilevel CFA and weighs, on the within level to indicate reliability of within-person change, the common variance of all items belonging to one factor by the total variance of all items (see Bolger \& Laurenceau, 2013); $\omega=.76$ and .92 for teaching factor F1 and F2, respectively, indicated good reliability.

Appraisals. One item for students' perception of control and two items for value (intrinsic and extrinsic) were included into the study. Appraisal items were based on previous investigations in the school context (Frenzel et al., 2007b; Pekrun et al., 2010) and were adapted to suit the current needs of the momentary assessment in the present study. Subjective control was assessed in relation to the subject of the specific lesson ("In this lesson, I am doing well in SUBJECT."), as was subjective value (either mathematics, physics, German or English lesson, see above). Value was differentiated into intrinsic value ("In this lesson, SUBJECT is very important to me, irrespective of the grade I get") and extrinsic value ("In this lesson, it is very important to me that I get a good grade in SUBJECT"). Items were rated on a five-point scale ranging from 1 (strongly disagree) to 5 (strongly agree).

Emotions. Students' class-related experiences of enjoyment, anxiety, and boredom were assessed using one item each ("How much EMOTION are you experiencing during this class?"). Assessing emotions by utilizing the emotion-word in the item stem is a common and effective research practice (Ahmed et al., 2010; Pekrun et al., 2011) that has been successfully used in previous ESM studies (Goetz, Frenzel, et al., 2010). Response format for these items was 1 (not at all) to 5 (very strongly).

Study 2.

Teaching characteristics. In Study 2, six characteristics of teaching assessed with a single item each served as indicators of students' perceptions of teaching. To best approximate the teaching factors derived from Study 1, the six items were assigned to two factors and we tested whether this model fit the data well via a confirmatory factor analysis (for further information, see Supplemental Materials S2 in the online supplemental material). Thus, items pertaining to understandability of teachers' explanations, teachers' enthusiasm, autonomy support, and goal clarity were assigned to the first factor, describing a supportive presentation style. The two items of difficulty and pace (too fast) were assigned to the second teaching factor, thus defining excessive lesson demands. The two factors showed adequate reliability ( $\omega=.69$ and .87 for teaching factor F1 and F2, respectively). Items for each factor were averaged across and introduced as manifest indicators in all subsequent analyses. All items were rated from 1 (strongly disagree) to 5 (strongly agree), with the exception of the item on difficulty, which was rated from 1 (too easy) to 5 (too difficult). ${ }^{3}$

Appraisals. Control as well as intrinsic and extrinsic value appraisals were assessed with one item each. Subjective control gauged students' momentarily perceived capability ("At the moment I am doing well in class"). Subjective value items gauged how important students found the activity itself (intrinsic value: "At the moment, this class is very important to me irrespective of grades"), as well as the outcome of the activity (extrinsic value: "At the moment it is very important to me to get good grades"). Response format for the appraisal items ranged from 1 (strongly disagree) to 5 (strongly agree).

Emotions. Momentary emotional experiences of enjoyment, anxiety, and boredom were assessed with one item per emotion ("At the moment, I am happy/anxious/bored"). This approach is similar to previous ESM-investigations on students' emotions (Goetz, Frenzel, et al., 2010). Items were rated on a five-point Likert scale ranging from 1 (strongly disagree) to 5 (strongly agree).

\section{Data Analysis}

Resulting from the ESM assessment of students' momentary classroom experiences, data in the two studies represented a nested data structure, with state assessments $(N=1,520 / 2,669$ in Study $1 /$ Study 2$)$ nested within students $(n=122 / 149)$. As such, measurements within persons are not independent from one another, which may result in an underestimation of standard errors and an increase in Type I errors (Snijders \& Bosker, 2012); as a consequence, the present study used a multilevel data analysis strategy.

To test the present study's main assumption, we ran withinperson mediation models with the two factors of teaching (supportive presentation style and excessive lesson demands) as predictors, appraisals of control and (intrinsic and extrinsic) value as

\footnotetext{
${ }^{3}$ In contrast to Study 1 , which assessed difficulty via the item "what is taught in this lesson is too difficult for me, rated from 1 (strongly disagree) to 5 (strongly agree), in Study 2 difficulty was assessed on a continuum from 1 (too easy) to 5 (too difficult). To check whether the present findings in study 2 were robust, we recoded the item's original levels 1,2 , and 3 $(1=$ too easy, $2=$ slightly too easy, $3=$ neither too easy nor too difficult $)$ into one level, resulting in a recoded three-level variable, ranging from not too difficult to too difficult. Thus, the recoded item in Study 2 more clearly resembles the difficulty item from Study 1 . Then we included the recoded difficulty item in teaching Factor 2 and compared the models' estimates to those with the original item and found them to be overall very similar.
} 
mediators and students' emotions (enjoyment, anxiety, boredom) as outcomes (see Figure 1). Thereby, we ran every model separately for each respective emotion, resulting in six mediation models overall, three each for Study 1 and Study 2. All analyses were conducted across the respective four subjects in the two studies (for subject-specific analyses, see Supplementary Materials S6 in the online supplemental material).

For the estimation of the mediation models, we used the Mplus software (Version 7.11; Muthén \& Muthén, 1998-2012) and the type is two level-option with maximum likelihood estimator. Missing data was accounted for by the full information maximum likelihood estimation. Class level was not taken into account in these analyses because only few students (two to four) per class participated in the study, and not all of these students participated in assessments during each of the lessons. In fact, the proportion of variance on the class level was very small for all variables and pattern of results remained largely unchanged when modeling two versus three levels. Prior to modeling in Mplus variables (teaching factors, appraisals, and emotions) were centered within persons (group-mean centering; see Enders \& Tofighi, 2007). This procedure was intended to eliminate the between-person variance of the variables and thus allowed for drawing conclusions on the intraindividual level (Bolger \& Laurenceau, 2013; see Aldrup, Klusmann, \& Lüdtke, 2017, for an application of multilevel withinsubject mediation analysis). All study variables were then modeled on the within-level whereby slopes were kept fixed (i.e., they did not vary between individuals).

\section{Results}

\section{Descriptive Statistics: Studies 1 and 2}

Means and standard deviations of Study 1 and Study 2 variables are reported in Table 1. Intraclass correlations (ICCs) are also shown. They denote the proportion of variance in the respective variable that lies on the between-person level. ICCs indicated that the majority of variance in all variables was on the within-level (i.e., measurement points nested within students), with ICCs ranging from $8 \%$ to $40 \%$.

Intercorrelations of study variables are presented in Table 2 and describe within-person relations among variables. To highlight a few links, the two teaching factors were negatively correlated in both studies to a moderate extent $(r=-.23$ and -.28 in Study 1 and Study 2, respectively). The three appraisals were positively interrelated, indicating that in situations in which a student experienced higher levels of control, he or she also experienced higher levels of intrinsic and extrinsic value, and higher levels of intrinsic value went along with higher levels of extrinsic value. The three discrete emotions interrelated within individuals along their valence-dimensions, with enjoyment being negatively correlated with the unpleasant emotions of anxiety $(r=-.13 /-.10)$ and boredom $(r=-.18 /-.22)$. At the same time the relation between the two unpleasant emotions was positive albeit negligible $(r=$ $.07 / .01)$.

\section{Total Effects: The Relation Between Teaching and Emotions-Studies 1 and 2}

Multilevel within-person mediation models were run for the two samples. The effects are shown in Figure 2 (for Study 1) and in Figure 3 (for Study 2) and describe partial effects (standard errors for displayed effects are included in the Supplementary Tables S3.1 and S3.2 in the online supplemental material). In other words, the effect of each predictor variable on any given outcome needs to be interpreted by taking the effects of all other predictor variables into account. The tested mediation models yielded total effects of teaching characteristics on students' emotions, reported in Table 3 (for standardized effects, see Supplemental Materials S4 in the online supplemental material). Total effects indicated that supportive presentation style (F1) related to higher levels of enjoyment (Study 1: $b=0.45$, Study 2: $b=0.38$ ) and lower levels of boredom $(b=-0.17 /-0.42)$. For anxiety there was no total

Table 1

Descriptive Statistics

\begin{tabular}{|c|c|c|c|c|c|c|}
\hline \multirow[b]{2}{*}{ Variable } & \multicolumn{3}{|c|}{ Study 1} & \multicolumn{3}{|c|}{ Study 2} \\
\hline & $M$ & $S D$ & ICC & $M$ & $S D$ & ICC \\
\hline \multicolumn{7}{|l|}{ Teaching factors } \\
\hline F1: Supportive presentation style & 3.05 & 1.08 & .22 & 3.08 & .77 & .27 \\
\hline F2: Excessive lesson demands & 1.81 & .89 & .13 & 2.52 & .90 & .17 \\
\hline \multicolumn{7}{|l|}{ Appraisals } \\
\hline Control & 2.86 & 1.33 & .14 & 3.24 & .98 & .19 \\
\hline Intrinsic value & 2.67 & 1.41 & .20 & 3.18 & 1.21 & .34 \\
\hline Extrinsic value & 2.74 & 1.52 & .28 & 3.51 & 1.19 & .40 \\
\hline \multicolumn{7}{|l|}{ Emotions } \\
\hline Enjoyment & 2.34 & 1.32 & .13 & 2.85 & 1.19 & .22 \\
\hline Anxiety & 1.42 & .95 & .08 & 1.45 & .93 & .26 \\
\hline Boredom & 3.06 & 1.45 & .13 & 2.56 & 1.29 & .29 \\
\hline
\end{tabular}

Note. $\quad \mathrm{ICC}=$ intraclass correlation. All items were rated on a scale ranging from 1 (strongly disagree) to 5 (strongly agree). Means and standard deviations for the teaching factors are based on manifest scales. Sample sizes were $N_{\text {states }}=1,520 / 2,669$ and $N_{\text {students }}=122 / 149$ for Study 1 and Study 2, respectively. Measurement points were nested within individuals (average cluster size 12.46/17.91), and variance was decomposed into a within-person component $\left(\sigma^{2}\right)$ and a between-person component $\left(\tau^{2}\right)$. The standard deviation is based on the total variance, whereas the intraclass correlation, ICC, gives the percentage of variance that lies on the between-level, ICC $=\frac{\tau^{2}}{\tau^{2}+\sigma^{2}}$. 
Table 2

Correlations of Study Variables

\begin{tabular}{lcccccrrr}
\hline \multicolumn{1}{c}{ Variable } & 1 & 2 & 3 & 4 & 5 & 6 & 7 & \multicolumn{1}{c}{8} \\
\hline 1. Supportive presentation style & $.90 / .44$ & -.28 & .36 & .34 & .13 & .27 & -.10 & -.24 \\
2. Excessive lesson demands & -.23 & $.67 / .68$ & -.45 & -.17 & .01 & -.19 & .20 & .01 \\
3. Control & .39 & -.26 & $1.51 / .78$ & .36 & .11 & .28 & -.15 & -.07 \\
4. Intrinsic value & .37 & -.05 & .32 & $1.58 / .98$ & .32 & .23 & -.05 & -.25 \\
5. Extrinsic value & .35 & .04 & .27 & .50 & $1.61 / .86$ & .07 & .05 & -.09 \\
6. Enjoyment & .38 & -.21 & .32 & .23 & .19 & $1.51 / 1.10$ & -.10 & -.22 \\
7. Anxiety & -.04 & .32 & -.08 & .02 & .10 & -.13 & $.82 / .64$ & .01 \\
8. Boredom & -.18 & .28 & -.07 & -.18 & -.11 & -.18 & .07 & $1.85 / 1.20$ \\
\hline
\end{tabular}

Note. All correlations refer to within-person that is intraindividual relations. Below diagonal correlations refer to Study 1 , above diagonal refer to Study 2. Values on the diagonal indicate the within-person variances $\left(\sigma^{2}\right)$ of the respective variable in Study 1 and Study 2.

effect of F1 in Study 1 and a negative effect in Study 2 $(b=-0.05)$. Excessive lesson demands (F2) showed the reverse pattern and related to lower levels of enjoyment $(b=$ $-0.20 /-0.16)$, and higher levels of anxiety $(b=0.36 / 0.19)$. For boredom, the total effect of F2 was positive in Study $1(b=0.43)$, yet negative in Study $2(b=-0.09)$.

\section{Appraisals as Mediators}

Relations between teaching and appraisals-Studies 1 and 2 . As evidenced in the multilevel within-person mediation model for Study 1 (see Figure 2) and Study 2 (see Figure 3), teaching situations that had been perceived by students as supportive (as indicated by the teaching factor $\mathrm{F} 1$ ), resulted in higher levels of control $(b=0.45 / 0.34$ for Study $1 /$ Study 2$)$, intrinsic value $(b=$ $0.50 / 0.48)$, and extrinsic value $(b=0.50 / 0.20)$, compared to teaching situations that had been perceived as less supportive by the same student. Conversely, excessive lesson demands (as indicated by the teaching factor F2) resulted in lower levels of control $(b=-0.27 /-0.40)$ and higher levels of extrinsic value $(b=$
$0.19 / 0.05)$ than less demanding lessons. There was no effect of F2 on intrinsic value in Study 1 and a negative effect $(b=-0.10)$ in Study 2.

Relations between appraisals and emotions-Studies 1 and 2. Analyses of within-person relations between appraisals and emotions revealed marked differences among the three emotions (see Figures 2 and 3). Whereas high levels of control and intrinsic value resulted in high levels of enjoyment $(b=0.17$ and 0.07 in Study $1 ; b=0.20$ and 0.12 in Study 2), there was no effect of extrinsic value on this emotion. For anxiety a different picture emerged: Extrinsic value positively related to anxiety $(b=0.08 /$ 0.05 in Study 1/Study 2) and control negatively related to anxiety (only in Study 2: $b=-0.08$ ), whereas intrinsic value did not relate to anxiety in either of the two samples. Finally, boredom showed yet another pattern of relations revealing that high levels of control went along with high levels of boredom $(b=$ $0.11 / 0.07)$, and high levels of intrinsic value went along with low levels of boredom $(b=-0.15 /-0.24)$. Extrinsic value was not related to boredom.

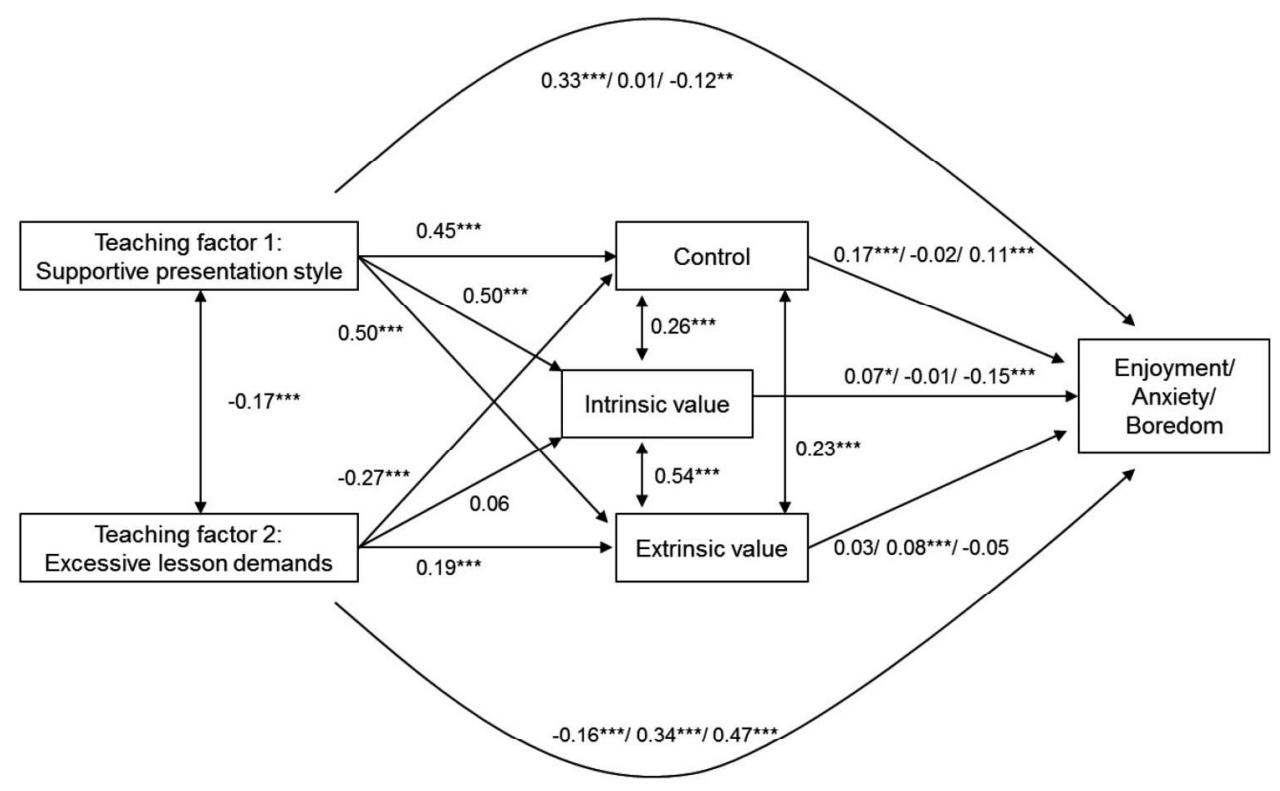

Figure 2. Unstandardized within-person effects of the multilevel mediation models in Study 1 for the three emotions enjoyment, anxiety, and boredom. ${ }^{*} p<.05 .{ }^{* *} p<.01 .{ }^{* * *} p<.001$. 


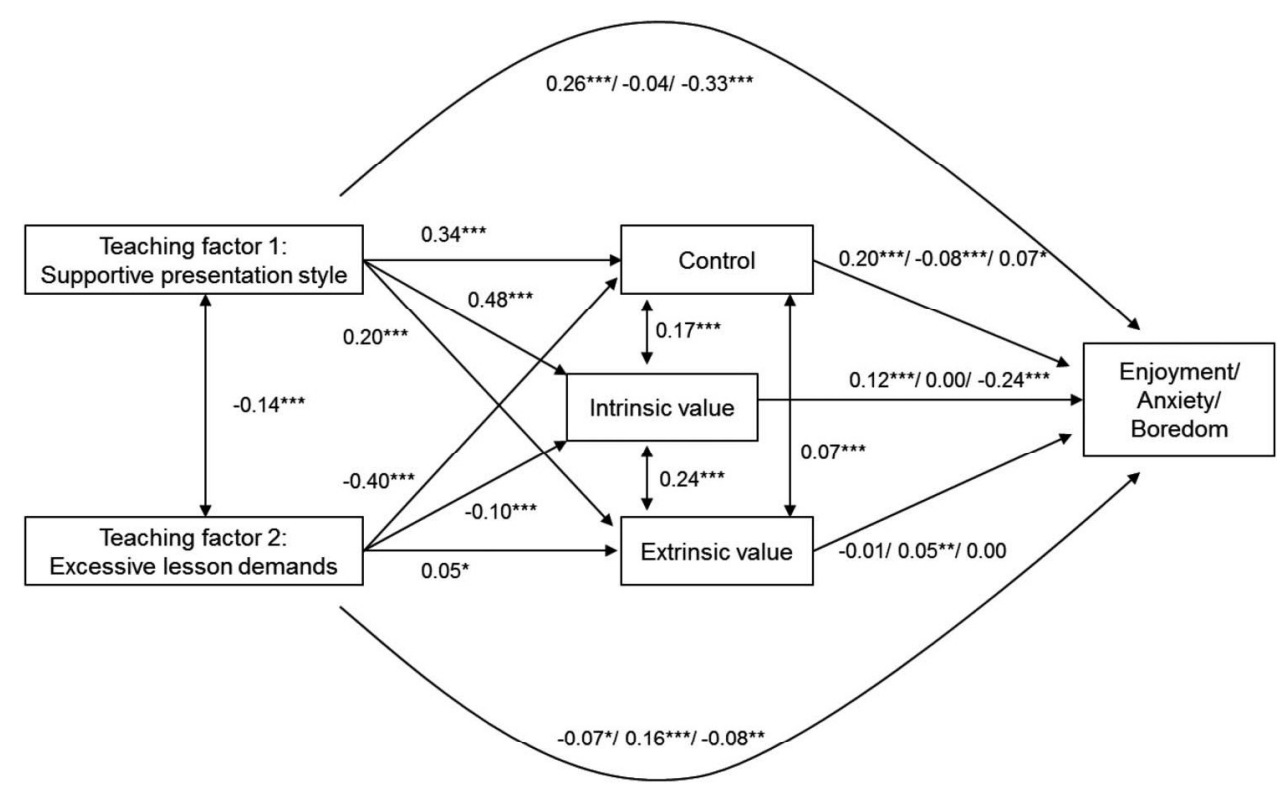

Figure 3. Unstandardized within-person effects of the multilevel mediation models in Study 2 for the three emotions enjoyment, anxiety, and boredom. ${ }^{*} p<.05 .{ }^{* *} p<.01 .{ }^{* * *} p<.001$.

Total indirect effects- Studies 1 and 2. As can be gleaned from the total indirect effects in Table 3, the effects of the two teaching factors on students' enjoyment, anxiety, and boredom were partially mediated through the appraisals of control, intrinsic, and extrinsic value. Specifically, teaching factor F1 representing the perception of a supportive learning environment, exerted a significant positive total indirect effect via all three appraisals on enjoyment $\left(b_{\text {ind }}=0.12 / 0.12\right.$ in Study $1 /$ Study 2$)$ and a negative total indirect effect on boredom $\left(b_{\text {ind }}=-0.05 /-0.09\right)$, whereas there was no total indirect effect on anxiety. Teaching factor F2, representing excessive demands, had overall negative total indirect effects on enjoyment $\left(b_{\text {ind }}=-0.04 /-0.09\right)$ and a positive total indirect effect on anxiety $\left(b_{\text {ind }}=0.02 / 0.03\right)$. The total indirect effect of teaching factor F2 on boredom was negative in Study 1 $\left(b_{\text {ind }}=-0.05\right)$, and not significant in Study 2 .

Specific indirect effects in Study 1. Breaking down total indirect effects along the three appraisals of control, intrinsic, and extrinsic value (specific indirect effects as reported in Table 3) revealed some differences among the three emotions. For students' enjoyment, the effects of teaching factors were mediated through control $\left(b_{\text {ind }}=0.07\right.$ and -0.04 for $\mathrm{F} 1$ and $\mathrm{F} 2$, respectively) and intrinsic value $\left(b_{\text {ind }}=0.04\right.$ for $\mathrm{F} 1$; no significant specific indirect effect of F2), but not through extrinsic value. For boredom, the identical pattern was revealed, with control $\left(b_{\text {ind }}=0.05\right.$ and -0.03$)$ and intrinsic value $\left(b_{\text {ind }}=-0.08\right.$ for $\mathrm{F} 1$; no significant specific indirect effect of F2), but not extrinsic value, mediating the effects of teaching factors on boredom. An altogether different pattern occurred for anxiety: Effects of the teaching factors were neither mediated through control nor through intrinsic value. Rather, the mediation of the two teaching factors was solely facilitated via extrinsic value $\left(b_{\text {ind }}=0.04\right.$ and 0.01 for $\mathrm{F} 1$ and $\mathrm{F} 2$, respectively).

Specific indirect effects in Study 2. Specific indirect effects for Study 2 revealed the differential role of appraisals with regards to the emotions in a similar way as in Study 1. For students' enjoyment, the influence of teaching factors was mediated through control $\left(b_{\text {ind }}=0.07\right.$ and -0.08 for $\mathrm{F} 1$ and $\mathrm{F} 2$, respectively) and intrinsic value $\left(b_{\text {ind }}=0.06\right.$ and -0.01$)$, but not through extrinsic value. The same pattern was revealed for boredom, where teaching exerted its influence through control $(b=0.02$ and -0.03$)$ and intrinsic value $\left(b_{\text {ind }}=0.11\right.$ and 0.02$)$, but not through extrinsic value. With regards to anxiety, the two teaching factors exerted specific indirect effects through control $\left(b_{\text {ind }}=-0.03\right.$ and 0.03$)$, whereas only a specific indirect effect through extrinsic value could be observed for teaching factor F1 $\left(b_{\text {ind }}=0.01\right)$ and not F2. Intrinsic value did not mediate relations between either teaching factor (i.e., F1 and F2) and students' anxiety.

Summary of mediated effects. Overall, the within-person effects of teaching (i.e., supportive presentation style and excessive lesson demands) on students' enjoyment, anxiety, and boredom were mediated through the appraisals of control, intrinsic, and extrinsic value in Study 1 and Study 2. In both studies herein reported the mediation was partial: There were significant direct effects of the two teaching factors on students' emotions when appraisals were accounted for as predictors of emotions (see Figures 2 and 3). Further-and as indicated by the specific indirect effects (see Table 3) - the specific appraisal constellation that facilitated the mediated effect of teaching on emotions depended on the emotion under question. For enjoyment and boredom, the effect of teaching was mediated primarily through control and intrinsic value, whereas the effect of teaching on anxiety was mediated largely through extrinsic value. Finally, the effect sizes, that is, the within-person explained variances in emotions, were overall moderate (see Table 3). Teaching factors and appraisals accounted for 5-19\% of within-person variance in emotions. Specifically, explained variance was lower for anxiety $\left(R^{2}=.11 / .05\right.$ in Study 1/Study 2$)$ and higher for enjoyment $\left(R^{2}=.19 / .13\right)$ and boredom $\left(R^{2}=.12 / .10\right)$. 


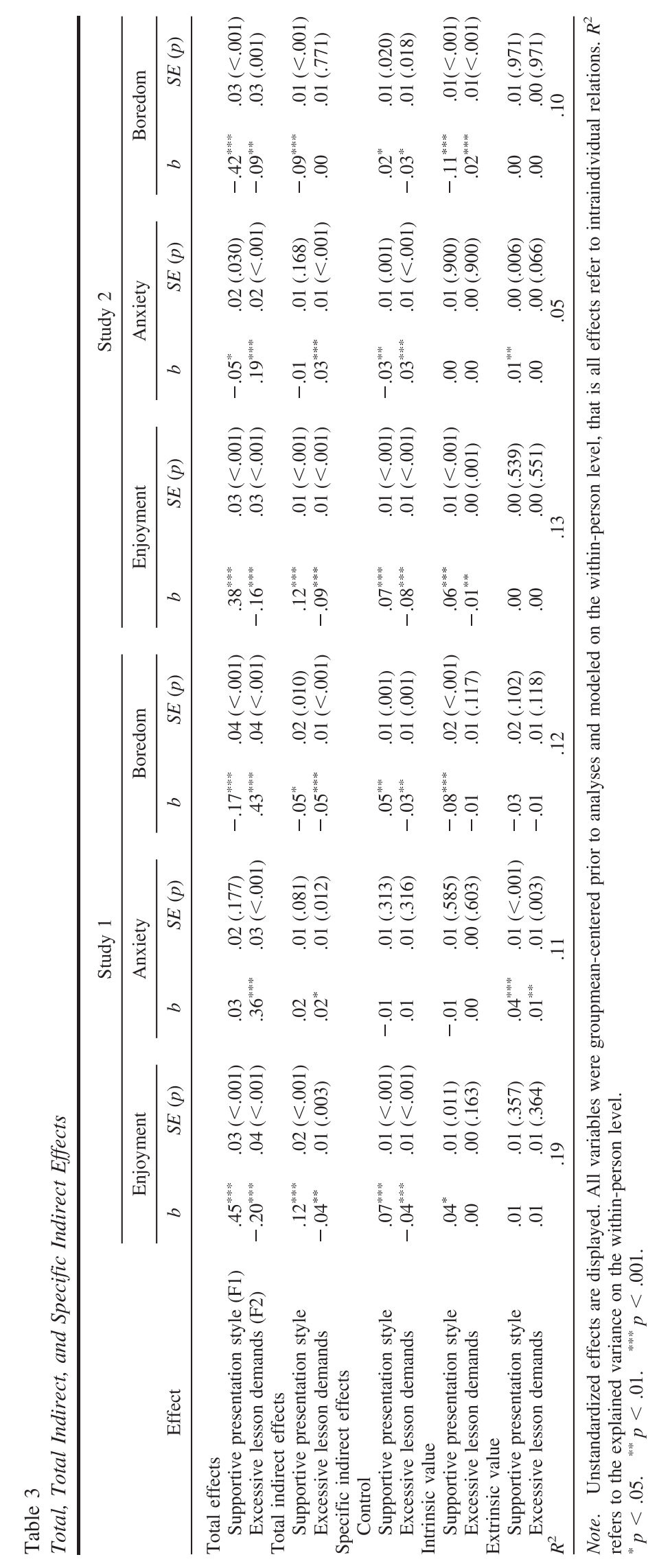




\section{Discussion}

The current study investigated whether control and value appraisals mediated the relation between student perceived teaching (i.e., teaching characteristics of "supportive presentation style," "excessive lesson demands") and students' prototypic academic emotions (i.e., enjoyment, anxiety, and boredom). To account for the dynamic nature of students' emotional experiences that vary from situation to situation (or lesson to lesson) we adopted the experience sampling method. Thus, we assessed perceptions and experiences of students' in situ, while they were in class. In Study 1 we used a sample of German high school students (see Goetz et al., 2013) to assess control and value (intrinsic and extrinsic) appraisals as potential mediators of teaching/emotions relations. In Study 2 we aimed to corroborate and extend the findings on the mediation mechanisms and gather initial evidence on the generalizability of the findings obtained in Study 1 by focusing on a different age of students and by collecting data in a different country (i.e., Switzerland).

Across the two studies we found a very consistent picture of results that supported our hypothesis. Appraisals of control, intrinsic, and extrinsic value partially mediated the intraindividual effects of the two teaching factors-supportive presentation style and excessive lesson demands-on students' experiences of enjoyment, anxiety, and boredom in the classroom. Although the two studies were based on samples of different age and nationalities, used different indicators for students' perceptions of teaching, and partly referred to different subject domains, the overall pattern of findings is remarkably similar across the two studies. Thereby, we found (a) that mediation of teaching via the appraisals of control and intrinsic and extrinsic value was partial; (b) that facets of teaching differ in the degree of direct versus indirect effects on specific student emotions; (c) depending on the emotion, different appraisals mediated the teaching-emotion relation; and (d) a unique mediation pattern for boredom.

To our knowledge, this is the first study showing the hypothesized mediation mechanisms with respect to intraindividual dynamics. The intraindividual approach could be captured by adopting the ESM (Hektner et al., 2007) as a real-time assessment tool of classroom experiences. ESM is characterized by high validity in sampling multiple assessments within each student during class (e.g., Bolger et al., 2003). Although the mediated effects seem small by comparison, it is important to note that they represent within-person effects and potentially accumulate over time. Because adolescents spend considerable time in classrooms, these cumulative within-person processes could in fact exert substantial effects on the individual over time; the extent to which these processes exert long-term impact is an open question, however, and requires further research.

\section{Partial Mediation}

We found appraisals of control and value to partially mediate the effects of student perceived teaching on students' emotions on an intraindividual level. The revealed partial mediation is supported by the theory and is in line with previous empirical findings. First, although we have selected core appraisals as outlined in Pekrun's (2006) CVT, there might be further facets of control (e.g., self-efficacy; Bong \& Skaalvik, 2003) and value (e.g., utility; Gaspard et al., 2015), which were not taken into account in our study and which could have contributed to the mediation above our selected variables.

Second, certain affectively toned facets of teacher behavior such as enthusiastic teaching can be assumed to impact students' emotions in a rather direct way via emotional contagion (Hatfield, Cacioppo, \& Rapson, 1993) or emotional crossover (Bakker \& Demerouti, 2013). The direct contagion effect has been demonstrated in previous studies, where teachers' enjoyment and enthusiastic teaching was shown to impact students' enjoyment (Frenzel et al., 2009; Keller, Goetz, Becker, Morger, \& Hensley, 2014). In our study, the direct contagion could have resulted in the relatively strong direct effect of the first teaching factor on student emotions, and consequently, a full mediation of teaching/emotions relations via cognitive appraisals was not observed. As such, a direct effect on students' emotions for specific teaching characteristics is theoretically plausible and empirically supported. In sum, our findings that appraisals of control, intrinsic, and extrinsic value partially mediate teaching/emotions relations are plausible and in line with the assumptions of the CVT (Pekrun, 2006).

\section{Mediation Patterns}

Two facets of the pattern of results are of pivotal importance with respect to our hypothesis: The relative importance of direct and indirect effects of the two teaching factors, and the relative importance of the three appraisals as mediators.

Relative importance of direct and indirect effects. The relative importance of direct and indirect effects of the two teaching factors on emotions was found to differ with respect to the specific emotion under investigation. At the same time the pattern of results was consistent across the two studies. For anxiety, the effect of supportive teaching style on anxiety was fully mediated by cognitive appraisals, whereas the effects of excessive lesson demands were partially mediated. For enjoyment and boredom, both factors were partially mediated in their effects on emotions. One reason for this result might be that with respect to its antecedents and effects, anxiety, as an unpleasant/activating emotion, might be more complex in nature than the more unidimensional unpleasant/ deactivating (i.e., boredom) and pleasant/activating (i.e., enjoyment) emotions. Pekrun (2006) described the ambivalent structure of this emotion and posits that anxiety as an unpleasant emotion may impair interest and intrinsic motivation, whereas as an activating emotion, it may induce extrinsic motivation to avoid failures. This complex structure of anxiety might also be mirrored in rather varying antecedent-emotion relationships. Thus, anxiety may be triggered more ambivalently by appraisal cognitions rather than by "simple" direct effects. Conversely, the direct effects would more likely hold true for boredom and enjoyment with both emotions being unidimensional in their effects and antecedents.

Thus, an important finding of our study is that facets of teaching differ in the degree of direct versus indirect effects on specific student emotions. Our knowledge of the relative importance of indirect and direct effects with respect to specific emotions might be important for programs focusing on enhancing or reducing a specific student emotion. Our results indicated that fostering a supportive teaching style may have a direct positive effect on enjoyment; still, there are significant indirect effects for enjoyment, which indicates that fostering appraisals needs to be taken into account as well. Anxiety is directly affected by excessive 
lesson demands and indirectly affected by both teaching factors, indicating that interventions should focus on enhancing facets of teaching that lead to emotionally sound appraisal constellations.

Relative importance of appraisal mediators. Specific appraisals seem to differ in their relative (that is as compared to other appraisals) importance as mediators. Specifically, in both of our studies, control and intrinsic but not extrinsic value (partially) mediated the effect of teaching on students' enjoyment and boredom. In regards to anxiety, extrinsic but not intrinsic value acted as a mediator (the finding concerning control as a mediator for anxiety was inconclusive, as it mediated the effects in Study 2 but not in Study 1).

The relative importance of different appraisals with respect to their role as mediators in teaching/emotions relations is of high practical relevance. Classroom interventions aiming to enhance or reduce a specific emotion in students might focus on optimizing teaching in a way that would foster appraisals aligned with optimal emotional profiles. As an alternative to modifying teaching behavior, interventions might focus directly on students' appraisals that are known to be main antecedents of specific emotions. For example, to reduce boredom, interventions could focus on enhancing students' intrinsic value by highlighting the personal relevance of the task or topic (Goetz, Hall, \& Krannich, 2019; Hulleman, Kosovich, Barron, \& Daniel, 2017). Anxiety interventions could attempt at decreasing students' extrinsic value, both via modifying teaching styles with corresponding effects on those appraisals such as reducing the salience of achievement outcomes in the classroom by adopting a mastery teaching approach (see, e.g., Meece, Anderman, \& Anderman, 2006) and/or via directly focusing on students' appraisals (e.g., via attributional retraining; Hall et al., 2007).

Opposite direct and indirect effects for boredom. For boredom, we observed a unique pattern in direct and indirect effects that was different from those for enjoyment and anxiety. In both studies supportive presentation style had an overall negative effect on boredom which was partially mediated. The negative effect of supportive presentation style was partially mediated via intrinsic value, yet the indirect effect via control was positive. Thus, the direct effect and the indirect effect via control were in opposite directions.

The negative direct effect can be explained by teacher enthusiasm, which is one of the defining characteristics of this type of teaching (Cui et al., 2017) and which may have directly reduced boredom without triggering any appraisal mediation mechanisms. The positive indirect effect via control, in turn, might stem from supportive teaching style resulting in excessively high levels of control, that may lead to students' feeling underchallenged which, in turn. may increase boredom. In fact, recent research has shown that boredom at school often occurred because of very low levels of challenge (e.g., Daschmann, Goetz, \& Stupnisky, 2011; Krannich et al., 2019).

In sum, our findings suggest that being supportive at school generally results in lower levels of boredom. However, this welcome reduction should be even higher if the potentially boredomincreasing indirect effect via (too strongly) enhanced control is avoided. Specifically, this means that when reducing students' boredom educators should consider students' individual capabilities and try and find the optimal level of challenge in teaching.

\section{Limitations and Future Directions}

Some limitations of the present study should be noted and can be used to suggest potential avenues for future research. First, in our study we exclusively relied on self-report data, which may have resulted in a common method bias (Podsakoff, MacKenzie, Lee, \& Podsakoff, 2003). Although we used a highly elaborated real-time assessment method, experience sampling is still a selfreport method. This might be of consequence specifically regarding the assessment of teaching via students' perceptions. To control for possible biases, future studies may include external assessments of classroom activities (via class-aggregated measures or classroom observations by trained raters using for instance the CLASS system, see Pianta \& Hamre, 2009) as a precursor to students' perceptions of teaching and the extent to which these two perspectives jointly or singularly predict students' appraisals or emotional experiences.

Second, by using the experience sampling method, some compromises had to be made that may have limited the interpretability of our findings. Specifically, to reduce intrusiveness of the ESM that was programmed to randomly signal during lessons for up to four students per class, we relied on single item assessments. Although this is not atypical for ESM studies (e.g., Goetz et al., 2013), it might nonetheless limit reliability of the assessed constructs. Although Gogol and colleagues (2014) and Wanous et al. (1997) did show that whenever long scales were not applicable, single-items worked sufficiently well, future studies may assess constructs using multiple indicators, thus potentially enhancing psychometric characteristics of assessments and allowing for more complex analyses.

Third, the use of the experience sampling method in combination with the analytical approach of within-person mediation do not allow for conclusions on the causal ordering of variables. Future studies in this field might combine assessment of short-term dynamics (similarly to the ESM used in our study) with developments over a longer time period (e.g., by using measurement-burst designs; Sliwinski, 2008) to be able to model growth processes or use dynamic structural equation models (Asparouhov, Hamaker, \& Muthén, 2018) to capture causal effects. Further, applying withinperson analyses answers frequent calls for focusing on withinperson processes in educational research (e.g., Schmitz, 2006) and complements existing research on the mediation assumption in CVT which generally relied on between-person analyses. It is critical to note that based on our analyses no generalizations can be made whether the same mediation patterns occur on the betweenperson level (see Voelkle et al., 2014, for a discussion of withinvs. between-person analyses). Thus, future research might dedicate itself to explicit comparisons of relations found on within- and between-person levels to advance our understanding of key educational processes and the necessary methodological designs and analytical approaches to study them.

Fourth, although the two studies were rather similar, there were some differences in study sample, variables, and item wordings. Whereas we found teaching perceptions, appraisal cognitions, and emotional experience of enjoyment, anxiety, and boredom to vary strongly within students across situations in both study samples (similar to previous findings, e.g., Ahmed et al., 2010; Goetz, Frenzel, et al., 2010; Nett et al., 2017), the extent of the withinperson variance in the two studies differed. Specifically, within- 
person variance was higher in Study 1 (German sample) than in Study 2 (Swiss sample; see Table 2).

This finding might reflect differences in samples, as percentage of student cohort attending Gymnasium is larger and thus presumably more heterogeneous in Germany than in Switzerland. Further, students from Grades 8 and 11 participated in Germany, whereas only students from Grade 9 in Switzerland. Differences in the assessment method could have also contributed to the revealed differences. So, item wording varied slightly, with Study 1 assessing students' experiences with regard to the present lesson (the specified time frame was "in this lesson"), whereas Study 2 assessments more strongly reflected students' momentary experiences (with "at the moment" being the specified time frame; see item wordings in Table A2 in the Appendix). In combination, these three issues (less heterogeneous student cohort, only one grade level, and smaller time frame in Study 2) may have contributed to smaller within-person variances in Study 2 compared to Study 1.

Specifically, the different assessment protocols would warrant a future study that could investigate whether the time frame captured by the item may generate differences and which time frame is optimal when targeting students' momentary experiences. Further, future research could examine whether and at what point expanding a time frame of an item would result in a shift from students' reliance on episodic to semantic knowledge, thus shifting from less state-like to more trait-like reports (Robinson \& Clore, 2002). We also found that intrinsic and extrinsic value appraisals had relatively high between-person variance components compared to other assessed variables; hence, it would be interesting to explore the extent to which momentary value appraisals are influenced by trait and valuerelated characteristics, such as individual interest.

Fifth, as a first step in analyzing the mediational role of cognitive appraisals in teaching/emotions relations we only investigated a restricted number of variables. Based on our findings and on further developments of the CVT (Pekrun, 2006), future studies may examine additional hypotheses of the mediational role of specific cognitive appraisals of control and value (for facets of control, see Bong \& Skaalvik, 2003; for value facets, see Gaspard et al., 2015) in the relations between specific teaching characteristics and specific emotions. Other potential mediators could also be examined - separately and in unison-with variables examined in our study. CVT postulates that control, value as well as the interaction of control and value relate to students' emotional experiences. We did not model this interaction effect due to the complexity of modeling two teaching factors as well as three appraisals simultaneously, yet future in-depth analyses could by means of moderated mediation analyses paint a comprehensive picture of the role different appraisals and appraisal constellations play in the elicitation of different emotions.

The restricted number of assessed variables is particularly salient for teaching characteristics: In identifying broad factors of supportive presentation style and excessive lesson demands, we were able to investigate the mediation hypotheses in an economic way and, more importantly, support assumptions made by CVT based on teaching characteristics outlined therein (i.e., cognitive quality and task demands). However, these teaching characteristics are not easily aligned to more normative and holistic approaches on what constitutes effective teaching (Kunter et al., 2013; Pianta \& Hamre, 2009), including three dimensions that Pianta and
Hamre (2009) labeled emotional support, classroom organization, and instructional support. Supportive presentation style, in focusing on aligning teaching to students' needs to support their learning, is somewhat reminiscent to social-emotional support dimensions of teaching (i.e., learning support in Kunter et al., 2013; emotional support in Pianta \& Hamre, 2009), yet also overlaps to some degree with the cognitive support dimensions (i.e., cognitive activation in Kunter et al., 2013; instructional support in Pianta \& Hamre, 2009). Conversely, the second teaching factor, excessive lesson demands, largely captures aspects of classroom organization (Pianta \& Hamre, 2009; classroom management in Kunter et al., 2013).

As such - and tentatively speaking considering the imprecise reframing of our teaching factors with regards to the three dimensions of effective teaching-emotional and instructional support of students was of relatively more relevance to the activity-related emotions of enjoyment and boredom, whereas aspects of classroom organization were highly influential with regards to students' anxiety (see Supplemental Tables S2.1 and S2.2 in the online supplemental material for standardized effects). This interpretation was partly corroborated by additional analyses (see Supplementary Materials S5 in the online supplemental material), in which we selected three single items for teaching to approximate the three dimensions of effective teaching (pacing as a proxy for classroom organization seemed to be more important regarding anxiety compared to enthusiasm as an aspect of emotional support and understandability as an aspect of instructional support). Future studies may focus on including a broader scope of teaching characteristics. This way, they could contribute to more strongly linking CVT and research on academic emotions within educational research.

Finally, the present study took a domain-independent approach, mainly based on prior evidence that the effect of teaching on emotions does not systematically differ between subject domains (Becker et al., 2014; Goetz et al., 2013). Still, differences between domains in the effect of appraisals on students' emotions can be expected in the way that control is more strongly related to emotions in the quantitative domains (mathematics and science) than in the verbal domain (e.g., languages; Goetz, Cronjaeger, Frenzel, Lüdtke, \& Hall, 2010). Taking this together with the finding that mathematics and science are perceived as demanding and difficult by students (Haag \& Götz, 2012; Kessels, Rau, \& Hannover, 2006), and with some studies finding that students experience more anxiety and less enjoyment in math than in languages (Becker et al., 2014; Goetz et al., 2013), leads to the assumption that there could be functional differences in appraisals as mediators between teaching and emotions across academic domains. Specifically, teaching characteristics that foster control such as coherence and scaffolding could exert a stronger effect on anxiety via control in mathematics and science than in languages. The current study lacks the power to investigate domain-specificity of effects on the within-person level; a domain-specific approach led to the tentative conclusion of no systematic domain differences (see Supplementary S6 in the online supplemental materials), yet future studies could dedicate to investigating domain specificity in the teaching-appraisal-emotion interrelations. 


\section{Implications for Further Developments of Pekrun's Control-Value Theory}

The present study may serve as a platform for further development of the CVT (Pekrun, 2006). Our results showed that specific control and value appraisals were effective mediators of specific teaching/emotions relations. Thus, a further development of the theory might be to differentiate teaching according to its inherent facets and describe direct and indirect effects on specific emotions via control and value appraisals. For example, teacher enthusiasm should be expected to have a strong direct but relatively week indirect (i.e., mediated) effect on enjoyment (because of emotional contagion; Hatfield et al., 1993). Conversely, a teaching style that activates value cognitions (e.g., extrinsic value-inducing teaching methods that refer to an upcoming exam) will be expected to have an indirect effect on a specific set of emotions such as anxiety. Further, for teaching factors that show indirect effects on specific emotions, main appraisals that mediate these effects need to be specified. For example, for students' experiences of boredom intrinsic value appraisals appear to play a crucial mediating role, hence, inducing intrinsic value may be of key importance. In sum, our results may be instrumental for the subsequent development and differentiation of the CVT (Pekrun, 2006). By outlining the relative role of direct and indirect (i.e., mediated) effects as well as the relative importance of specific appraisals in the relations between specific teaching styles and discrete emotions, the theory could be further expanded.

\section{References}

Ahmed, W., van der Werf, G., Minnaert, A., \& Kuyper, H. (2010). Students' daily emotions in the classroom: Intra-individual variability and appraisal correlates. British Journal of Educational Psychology, 80, 583-597. http://dx.doi.org/10.1348/000709910X498544

Aldrup, K., Klusmann, U., \& Lüdtke, O. (2017). Does basic need satisfaction mediate the link between stress exposure and well-being? A diary study among beginning teachers. Learning and Instruction, 50, 21-30. http://dx.doi.org/10.1016/j.learninstruc.2016.11.005

Asparouhov, T., Hamaker, E. L., \& Muthén, B. (2018). Dynamic structural equation models. Structural Equation Modeling, 25, 359-388. http://dx .doi.org/10.1080/10705511.2017.1406803

Assor, A., Kaplan, H., Kanat-Maymon, Y., \& Roth, G. (2005). Directly controlling teacher behaviors as predictors of poor motivation and engagement in girls and boys: The role of anger and anxiety. Learning and Instruction, 15, 397-413. http://dx.doi.org/10.1016/j.learninstruc.2005 .07 .008

Bakker, A. B. (2005). Flow among music teachers and their students: The crossover of peak experiences. Journal of Vocational Behavior, 66, 26-44. http://dx.doi.org/10.1016/j.jvb.2003.11.001

Bakker, A. B., \& Demerouti, E. (2013). The spillover-crossover model. In J. Grzywacz \& E. Demerouti (Eds.), New frontiers in work and family research (pp. 54-70). Hove, UK: Psychology Press.

Barrett, L. F., \& Barrett, D. J. (2001). An introduction to computerized experience sampling in psychology. Social Science Computer Review, 19, 175-185. http://dx.doi.org/10.1177/089443930101900204

Becker, E., Goetz, T., Morger, V., \& Ranellucci, J. (2014). The importance of teachers' emotions and instructional behavior for their students' emotions: An experience sampling analysis. Teaching and Teacher Education, 43, 15-26. http://dx.doi.org/10.1016/j.tate.2014.05.002

Bergin, D. A. (1999). Influences on classroom interest. Educational Psychologist, 34, 87-98. http://dx.doi.org/10.1207/s15326985ep3402_2
Black, A. E., \& Deci, E. L. (2000). The effects of instructors' autonomy support and students' autonomous motivation on learning organic chemistry: A self-determination theory perspective. Science Education, 84, 740-756. http://dx.doi.org/10.1002/1098-237X(200011)84:6<740:: AID-SCE4>3.0.CO;2-3

Boehme, K. L., Goetz, T., \& Preckel, F. (2017). Is it good to value math? Investigating mothers' impact on their children's test anxiety based on control-value theory. Contemporary Educational Psychology, 51, 1121. http://dx.doi.org/10.1016/j.cedpsych.2017.05.002

Bolger, N., Davis, A., \& Rafaeli, E. (2003). Diary methods: Capturing life as it is lived. Annual Review of Psychology, 54, 579-616. http://dx.doi .org/10.1146/annurev.psych.54.101601.145030

Bolger, N., \& Laurenceau, J.-P. (2013). Intensive longitudinal methods: An introduction to diary and experience sampling research. New York, NY: Guilford Press.

Bong, M., \& Skaalvik, E. M. (2003). Academic self-concept and selfefficacy: How different are they really? Educational Psychology Review, 15, 1-40. http://dx.doi.org/10.1023/A:1021302408382

Burić, I. (2015). The role of social factors in shaping students' test emotions: A mediation analysis of cognitive appraisals. Social Psychology of Education: An International Journal, 18, 785-809. http://dx.doi .org/10.1007/s11218-015-9307-9

Csikszentmihalyi, M., \& Larson, R. (1987). Validity and reliability of the experience-sampling method. Journal of Nervous and Mental Disease, 175, 526-536. http://dx.doi.org/10.1097/00005053-198709000-00004

Cui, G., Yao, M., \& Zhang, X. (2017). The dampening effects of perceived teacher enthusiasm on class-related boredom: The mediating role of perceived autonomy support and task value. Frontiers in Psychology, 8, 400. http://dx.doi.org/10.3389/fpsyg.2017.00400

Daschmann, E. C., Goetz, T., \& Stupnisky, R. H. (2011). Testing the predictors of boredom at school: Development and validation of the precursors to boredom scales. British Journal of Educational Psychology, 81, 421-440. http://dx.doi.org/10.1348/000709910X526038

Eid, M., \& Diener, E. (1999). Intraindividual variability in affect: Reliability, validity, and personality correlates. Journal of Personality and Social Psychology, 76, 662-676. http://dx.doi.org/10.1037/0022-3514 .76.4.662

Ellsworth, P. C., \& Scherer, K. R. (2003). Appraisal processes in emotion In H. H. Goldsmith, K. R. Scherer, \& R. J. Davidson (Eds.), Handbook of affective sciences (pp. 572-595). Oxford, UK: Oxford University Press.

Enders, C. K., \& Tofighi, D. (2007). Centering predictor variables in cross-sectional multilevel models: A new look at an old issue. Psychological Methods, 12, 121-138. http://dx.doi.org/10.1037/1082-989X.12 .2 .121

Frenzel, A. C., Goetz, T., Lüdtke, O., Pekrun, R., \& Sutton, R. E. (2009) Emotional transmission in the classroom: Exploring the relationship between teacher and student enjoyment. Journal of Educational Psychology, 101, 705-716. http://dx.doi.org/10.1037/a0014695

Frenzel, A. C., Pekrun, R., \& Goetz, T. (2007a). Perceived learning environment and students' emotional experiences: A multilevel analysis of mathematics classrooms. Learning and Instruction, 17, 478-493. http://dx.doi.org/10.1016/j.learninstruc.2007.09.001

Frenzel, A. C., Pekrun, R., \& Goetz, T. (2007b). Girls and mathematics-a "hopeless" issue? A control-value approach to gender differences in emotions towards mathematics. European Journal of Psychology of Education, 22, 497-514. http://dx.doi.org/10.1007/BF03173468

Frenzel, A. C., \& Stephens, E. J. (2013). Emotions. In N. C. Hall \& T. Goetz (Eds.), Emotion, motivation, and self-regulation: A handbook for teachers (pp. 1-56). Bingley, UK: Emerald.

Gaspard, H., Dicke, A.-L., Flunger, B., Schreier, B., Häfner, I., Trautwein, U., \& Nagengast, B. (2015). More value through greater differentiation: Gender differences in value beliefs about math. Journal of Educational Psychology, 107, 663-677. http://dx.doi.org/10.1037/edu0000003 
Goetz, T., Cronjaeger, H., Frenzel, A. C., Lüdtke, O., \& Hall, N. (2010). Academic self-concept and emotion relations: Domain specificity and age effects. Contemporary Educational Psychology, 35, 44-58. http:// dx.doi.org/10.1016/j.cedpsych.2009.10.001

Goetz, T., Frenzel, A. C., Hall, N. C., Nett, U. E., Pekrun, R., \& Lipnevich, A. A. (2014). Types of boredom: An experience sampling approach. Motivation and Emotion, 38, 401-419. http://dx.doi.org/10.1007/ s11031-013-9385-y

Goetz, T., Frenzel, A. C., Stoeger, H., \& Hall, N. (2010). Antecedents of everyday positive emotions: An experience sampling analysis. Motivation and Emotion, 34, 49-62. http://dx.doi.org/10.1007/s11031-009$9152-2$

Goetz, T., Hall, N. C., \& Krannich, M. (2019). Boredom. In A. Renninger \& S. Hidi (Eds.), Cambridge handbook on motivation and learning (pp. 465-486). Cambridge, UK: Cambridge University Press. http://dx.doi .org/10.1017/9781316823279.021

Goetz, T., Lüdtke, O., Nett, U. E., Keller, M., \& Lipnevich, A. (2013). Characteristics of teaching and students' emotions in the classroom: Investigating differences across domains. Contemporary Educational Psychology, 38, 383-394. http://dx.doi.org/10.1016/j.cedpsych.2013.08 .001

Goetz, T., Pekrun, R., Hall, N., \& Haag, L. (2006). Academic emotions from a social-cognitive perspective: Antecedents and domain specificity of students' affect in the context of Latin instruction. British Journal of Educational Psychology, 76, 289-308. http://dx.doi.org/10.1348/0007 09905X42860

Gogol, K., Brunner, M., Goetz, T., Martin, R., Ugen, S., Keller, U., . . Preckel, F. (2014). "My questionnaire is too long!”: The assessments of motivational-affective constructs with three-item and single-item measures. Contemporary Educational Psychology, 39, 188-205. http://dx .doi.org/10.1016/j.cedpsych.2014.04.002

Gogol, K., Brunner, M., Martin, R., Preckel, F., \& Goetz, T. (2017). Affect and motivation within and between school subjects: Development and validation of an integrative model. Contemporary Educational Psychology, 49, 46-65. http://dx.doi.org/10.1016/j.cedpsych.2016.11.003

Haag, L., \& Götz, T. (2012). Mathe ist schwierig und Deutsch aktuell: Vergleichende Studie zur Charakterisierung von Schulfächern aus Schülersicht [Math is difficult and German up to date: A study on the characterization of subject domains from students' perspective]. Psychologie in Erziehung und Unterricht, 59, 32-46. http://dx.doi.org/10 .2378/peu2012.art03d

Hall, N. C., Perry, R. P., Goetz, T., Ruthig, J. C., Stupinsky, R. H., \& Newall, N. E. (2007). Attributional retraining and elaborative learning: Improving academic development through writing-based interventions. Learning and Individual Differences, 17, 280-290. http://dx.doi.org/10 1016/j.lindif.2007.04.002

Hatfield, E., Cacioppo, J. T., \& Rapson, R. L. (1993). Emotional contagion. Current Directions in Psychological Science, 2, 96-100. http://dx.doi .org/10.1111/1467-8721.ep10770953

Hektner, J. M., Schmidt, J. A., \& Csikszentmihalyi, M. (Eds.). (2007). Experience sampling method: Measuring the quality of everyday life. Thousand Oaks, CA: Sage. http://dx.doi.org/10.4135/9781412984201

Hulleman, C. S., Kosovich, J. J., Barron, K. E., \& Daniel, D. B. (2017). Making connections: Replicating and extending the utility value intervention in the classroom. Journal of Educational Psychology, 109, 387-404. http://dx.doi.org/10.1037/edu0000146

Keller, M. M., Goetz, T., Becker, E., Morger, V., \& Hensley, L. (2014). Feeling and showing: A new conceptualization of dispositional teacher enthusiasm and its relation to students' interest. Learning and Instruction, 33, 29-38. http://dx.doi.org/10.1016/j.learninstruc.2014.03.001

Kessels, U., Rau, M., \& Hannover, B. (2006). What goes well with physics? Measuring and altering the image of science. British Journal of Educational Psychology, 76, 761-780. http://dx.doi.org/10.1348/ $000709905 X 59961$
Krannich, M., Goetz, T., Roos, A.-L., Murayama, K., Keller, M. M., Bieg, M., \& Lipnevich, A. A. (2019). The predictive validity of state versus trait challenge and boredom for career aspirations. Manuscript submitted for publication.

Kunter, M., \& Baumert, J. (2007). Who is the expert? Construct and criteria validity of student and teacher ratings of instruction. Learning Environments Research, 9, 231-251. http://dx.doi.org/10.1007/s10984006-9015-7

Kunter, M., Klusmann, U., Baumert, J., Richter, D., Voss, T., \& Hachfeld, A. (2013). Professional competence of teachers: Effects on instructional quality and student development. Journal of Educational Psychology, 105, 805-820. http://dx.doi.org/10.1037/a0032583

Lazarus, R. S. (1991). Cognition and motivation in emotion. American Psychologist, 46, 352-367. http://dx.doi.org/10.1037/0003-066X.46.4 .352

Long, G. (1991). Epictetus: Enchiridion. Amherst, NY: Prometheus Books.

Meece, J. L., Anderman, E. M., \& Anderman, L. H. (2006). Classroom goal structure, student motivation, and academic achievement. Annиal Review of Psychology, 57, 487-503. http://dx.doi.org/10.1146/annurev .psych.56.091103.070258

Molenaar, P. C. M., \& Campbell, C. G. (2009). The new person-specific paradigm in psychology. Current Directions in Psychological Science, 18, 112-117. http://dx.doi.org/10.1111/j.1467-8721.2009.01619.x

Moors, A. (2009). Theories of emotion causation: A review. Cognition and Emotion, 23, 625-662. http://dx.doi.org/10.1080/02699930802645739

Mouratidis, A. A., Vansteenkiste, M., Sideridis, G., \& Lens, W. (2011). Vitality and interest-enjoyment as a function of class-to-class variation in need-supportive teaching and pupils' autonomous motivation. Journal of Educational Psychology, 103, 353-366. http://dx.doi.org/10.1037/ a0022773

Murayama, K., Goetz, T., Malmberg, L.-E., Pekrun, R., Tanaka, A., \& Martin, A. J. (2017). Within-person analysis in educational psychology: Importance and illustrations. British Journal of Educational Psychology, $12,71-87$.

Muthén, B. O., \& Muthén, L. K. (1998-2012). Mplus user's guide ( $7^{\text {th }}$ ed.) Los Angeles, CA: Author.

Nett, U. E., Bieg, M., \& Keller, M. M. (2017). How much trait variance is captured by measures of academic state emotions. European Journal of Psychological Assessment, 33, 239-255. http://dx.doi.org/10.1027/ 1015-5759/a000416

OECD. (2017). Education at a glance 2017: OECD indicators. Paris, France: OECD Publishing.

Pekrun, R. (2006). The control-value theory of achievement emotions: Assumptions, corollaries, and implications for educational research and practice. Educational Psychology Review, 18, 315-341. http://dx.doi .org/10.1007/s10648-006-9029-9

Pekrun, R., Goetz, T., Daniels, L. M., Stupnisky, R. H., \& Perry, R. P. (2010). Boredom in achievement settings: Exploring control-value antecedents and performance outcomes of a neglected emotion. Journal of Educational Psychology, 102, 531-549. http://dx.doi.org/10.1037/ a0019243

Pekrun, R., Goetz, T., Frenzel, A. C., Barchfeld, P., \& Perry, R. P. (2011) Measuring emotions in students' learning and performance: The Achievement Emotions Questionnaire (AEQ). Contemporary Educational Psychology, 36, 36-48. http://dx.doi.org/10.1016/j.cedpsych 2010.10.002

Pekrun, R., Goetz, T., Titz, W., \& Perry, R. P. (2002). Academic emotions in students' self-regulated learning and achievement: A program of qualitative and quantitative research. Educational Psychologist, 37, 91105. http://dx.doi.org/10.1207/S15326985EP3702_4

Pekrun, R., Hall, N. C., Goetz, T., \& Perry, R. P. (2014). Boredom and academic achievement: Testing a model of reciprocal causation. Journal 
of Educational Psychology, 106, 696-710. http://dx.doi.org/10.1037/ a0036006

Pekrun, R., Lichtenfeld, S., Marsh, H. W., Murayama, K., \& Goetz, T. (2017). Achievement emotions and academic performance: Longitudinal models of reciprocal effects. Child Development, 88, 1653-1670. http:// dx.doi.org/10.1111/cdev.12704

Pekrun, R., Muis, K. R., Frenzel, A. C., \& Goetz, T. (2018). Emotions at school. New York, NY: Routledge.

Pianta, R. C., \& Hamre, B. K. (2009). Conceptualization, measurement, and improvement of classroom processes: Standardized observation can leverage capacity. Educational Researcher, 38, 109-119. http://dx.doi .org/10.3102/0013189X09332374

Podsakoff, P. M., MacKenzie, S. B., Lee, J.-Y., \& Podsakoff, N. P. (2003). Common method biases in behavioral research: A critical review of the literature and recommended remedies. Journal of Applied Psychology, 88, 879-903. http://dx.doi.org/10.1037/0021-9010.88.5.879

Praetorius, A.-K., Lenske, G., \& Helmke, A. (2012). Observer ratings of instructional quality: Do they fulfill what they promise? Learning and Instruction, 22, 387-400. http://dx.doi.org/10.1016/j.learninstruc.2012 .03 .002

Robinson, M. D., \& Clore, G. L. (2002). Belief and feeling: Evidence for an accessibility model of emotional self-report. Psychological Bulletin, 128, 934-960. http://dx.doi.org/10.1037/0033-2909.128.6.934

Schmitz, B. (2006). Advantages of studying processes in educational research. Learning and Instruction, 16, 433-449. http://dx.doi.org/10 $.1016 /$ j.learninstruc.2006.09.004

Skinner, E. A. (1996). A guide to constructs of control. Journal of Personality and Social Psychology, 71, 549-570. http://dx.doi.org/10.1037/ 0022-3514.71.3.549

Sliwinski, M. J. (2008). Measurement-burst designs for social health research. Social and Personality Psychology Compass, 2, 245-261. http:// dx.doi.org/10.1111/j.1751-9004.2007.00043.x

Snijders, T. A. B., \& Bosker, R. J. (2012). Multilevel analysis. London, UK: Sage Ltd.
Taylor, B. A., \& Fraser, B. J. (2013). Relationships between learning environment and mathematics anxiety. Learning Environments Research, 16, 297-313. http://dx.doi.org/10.1007/s10984-013-9134-x

Tong, E. M. W., Bishop, G. D., Enkelmann, H. C., Why, Y. P., Diong, S. M., Khader, M., \& Ang, J. (2005). The use of ecological momentary assessment to test appraisal theories of emotion. Emotion, 5, 508-512. http://dx.doi.org/10.1037/1528-3542.5.4.508

Tong, E. M. W., Bishop, G. D., Enkelmann, H. C., Why, Y. P., Diong, S. M., Khader, M., \& Ang, J. (2007). Emotion and appraisal: A study using ecological momentary assessment. Cognition and Emotion, 21, 1361-1381. http://dx.doi.org/10.1080/02699930701202012

Voelkle, M. C., Brose, A., Schmiedek, F., \& Lindenberger, U. (2014). Toward a unified framework for the study of between-person and within-person structures: Building a bridge between two research paradigms. Multivariate Behavioral Research, 49, 193-213. http://dx.doi .org/10.1080/00273171.2014.889593

Wagner, W., Göllner, R., Helmke, A., Trautwein, U., \& Lüdtke, O. (2013) Construct validity of student perceptions of instructional quality is high, but not perfect: Dimensionality and generalizability of domainindependent assessments. Learning and Instruction, 28, 1-11. http://dx .doi.org/10.1016/j.learninstruc.2013.03.003

Wagner, W., Göllner, R., Werth, S., Voss, T., Schmitz, B., \& Trautwein, U. (2016). Student and teacher ratings of instructional quality: Consistency of ratings over time, agreement, and predictive power. Journal of Educational Psychology, 108, 705-721. http://dx.doi.org/10.1037/ edu0000075

Wanous, J. P., Reichers, A. E., \& Hudy, M. J. (1997). Overall job satisfaction: How good are single-item measures? Journal of Applied Psychology, 82, 247-252. http://dx.doi.org/10.1037/0021-9010.82.2.247

Zeidner, M. (2007). Test anxiety in educational contexts: Concepts, findings, and future directions. In P. A. Schutz \& R. Pekrun (Eds.), Emotion in education (pp. 165-184). Amsterdam, the Netherlands: Elsevier. http://dx.doi.org/10.1016/B978-012372545-5/50011-3 


\section{Appendix}

Item Wordings for Studies 1 and 2

Table A1

Item Wordings for Study 1

\begin{tabular}{|c|c|}
\hline Item & Item wording \\
\hline \multicolumn{2}{|c|}{ Teaching factor F1: Supportive presentation style } \\
\hline Understandability & $\begin{array}{l}\text { In this lesson, our teacher's vocabulary is easy to understand. } \\
\text { Unser Lehrer drückt sich in dieser Stunde verständlich aus. }\end{array}$ \\
\hline Enthusiasm & $\begin{array}{l}\text { In this lesson, our teacher presents the material with enthusiasm. } \\
\text { Unser Lehrer unterrichtet in dieser Stunde mit Begeisterung. }\end{array}$ \\
\hline Illustration & $\begin{array}{l}\text { In this lesson, our teacher explains the material in such a way that I can picture in my mind how things work. } \\
\text { Unser Lehrer erklärt den Stoff in dieser Stunde so, dass ich mir anschaulich vorstellen kann, wie es geht. }\end{array}$ \\
\hline Fostering attention & $\begin{array}{l}\text { In this lesson, our teacher makes sure that we pay attention. } \\
\text { Unser Lehrer achtet in dieser Stunde darauf, dass wir aufpassen. }\end{array}$ \\
\hline \multicolumn{2}{|c|}{ Teaching factor F2: Excessive lesson demands } \\
\hline Difficulty & $\begin{array}{l}\text { What is taught in this lesson is too difficult for me. } \\
\text { Das, was wir in dieser Stunde durchnehmen, ist zu schwierig für mich. }\end{array}$ \\
\hline Pace & $\begin{array}{l}\text { The pace of this lesson is too fast for me. } \\
\text { Der Unterricht geht in dieser Stunde so schnell weiter, dass ich Schwierigkeiten habe, mitzukommen. }\end{array}$ \\
\hline Lack of clarity & $\begin{array}{l}\text { In this lesson, our teacher's instruction are so unclear, that I don't know what I have to do. } \\
\text { Unser Lehrer gibt in dieser Stunde so unklare Anweisungen, dass ich nicht weiß, was ich tun muss. }\end{array}$ \\
\hline \multicolumn{2}{|r|}{ 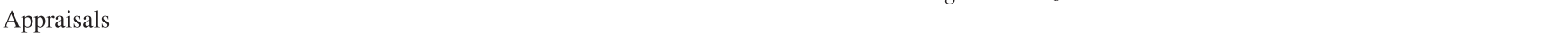 } \\
\hline Control & $\begin{array}{l}\text { In this lesson, I am doing well in SUBJECT. } \\
\text { In dieser Stunde bin ich gut in FACH. }\end{array}$ \\
\hline Intrinsic value & $\begin{array}{l}\text { In this lesson, SUBJECT is very important to me, irrespective of the grade I get. } \\
\text { Egal, welche Note ich bekommen, FACH ist mir in dieser Stunde sehr wichtig. }\end{array}$ \\
\hline Extrinsic value & $\begin{array}{l}\text { In this lesson, it is very important to me that I get a good grade in SUBJECT. } \\
\text { Mir ist es in dieser Stunde sehr wichtig, dass ich in FACH eine gute Note bekomme. }\end{array}$ \\
\hline \multicolumn{2}{|r|}{ 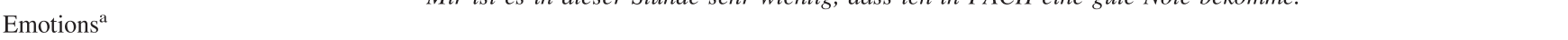 } \\
\hline Enjoyment & $\begin{array}{l}\text { How much enjoyment are you experiencing in this class? } \\
\text { Wie stark erlebst du in dieser Unterrichtsstunde Freude? }\end{array}$ \\
\hline Anxiety & $\begin{array}{l}\text { How much anxiety are you experiencing in this class? } \\
\text { Wie stark erlebst du in dieser Unterrichtsstunde Angst? }\end{array}$ \\
\hline Boredom & $\begin{array}{l}\text { How much boredom are you experiencing in this class? } \\
\text { Wie stark erlebst du in dieser Unterrichtsstunde Langeweile? }\end{array}$ \\
\hline
\end{tabular}

Note. Item wordings give the original German wording (in italics) as well as their translation to English. All items unless otherwise indicated were rated from 1 (strongly disagree) to 5 (strongly agree).

${ }^{a}$ Emotion items were rated from 1 (not at all [gar nicht]) to 5 (very strongly [sehr stark]). 
Table A2

Item Wordings for Study 2

\begin{tabular}{|c|c|}
\hline Item & Item wording \\
\hline \multicolumn{2}{|c|}{ Teaching factor F1: Supportive presentation style } \\
\hline Understandability & $\begin{array}{l}\text { At the moment, my teacher is explaining things in a comprehensible way. } \\
\text { Die Unterrichtsinhalte werden im Moment verständlich dargeboten. }\end{array}$ \\
\hline Enthusiasm & $\begin{array}{l}\text { At the moment, my teacher is teaching with enthusiasm. } \\
\text { Meine Lehrperson unterrichtet im Moment mit Begeisterung }\end{array}$ \\
\hline Autonomy & $\begin{array}{l}\text { At the moment I have the opportunity to choose and to co-decide in this class. } \\
\text { Im Moment habe ich Auswahl- und Entscheidungsmöglichkeiten im Unterricht. }\end{array}$ \\
\hline Goal clarity & $\begin{array}{l}\text { At the moment, I understand the aims and goals of this lesson. } \\
\text { Im Moment sind mir die Absichten und Ziele des Unterrichts klar. }\end{array}$ \\
\hline \multicolumn{2}{|c|}{ Teaching factor F2: Excessive lesson demands } \\
\hline Difficulty & $\begin{array}{l}\text { At the moment, the class is too easy-too difficult for me. }{ }^{\mathrm{a}} \\
\text { Im Moment empfinde ich den Schwierigkeitsgrad im Unterricht als zu einfach-zu schwierig. }\end{array}$ \\
\hline Pace & $\begin{array}{l}\text { At the moment, this lesson's pace is so high that I have difficulties getting along. } \\
\text { Der Unterricht geht im Moment so schnell weiter, dass ich Schwierigkeiten habe mitzukommen. }\end{array}$ \\
\hline \multicolumn{2}{|r|}{ 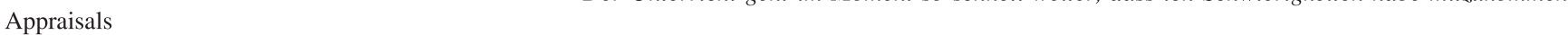 } \\
\hline Control & $\begin{array}{l}\text { At the moment I am doing well in class. } \\
\text { Im Moment bin ich gut im Unterricht. }\end{array}$ \\
\hline Intrinsic value & $\begin{array}{l}\text { At the moment, this class is very important to me irrespective of grades. } \\
\text { Der Unterricht ist mir im Moment unabhängig von der Note sehr wichtig. }\end{array}$ \\
\hline Extrinsic value & $\begin{array}{l}\text { At the moment it is very important to me to get good grades. } \\
\text { Mir ist es im Moment sehr wichtig, dass ich eine gute Note bekomme. }\end{array}$ \\
\hline \multicolumn{2}{|r|}{ Fen } \\
\hline Enjoyment & $\begin{array}{l}\text { At the moment, I am happy. } \\
\text { Im Moment freue ich mich. }\end{array}$ \\
\hline Anxiety & $\begin{array}{l}\text { At the moment, I am anxious. } \\
\text { Im Moment habe ich Angst. }\end{array}$ \\
\hline Boredom & $\begin{array}{l}\text { At the moment, I am bored. } \\
\text { Im Moment langweile ich mich. }\end{array}$ \\
\hline
\end{tabular}

Note. Item wordings give the original German wording (in italics) as well as their translation to English. All items unless otherwise indicated were rated from 1 (strongly disagree) to 5 (strongly agree).

${ }^{\text {a }}$ This item was rated from 1 (too easy (zu einfach]) to 5 (too difficult (zu schwierig]). 